\title{
Hopf Bifurcation Control of Subsynchronous Resonance Utilizing UPFC
}

\author{
Majdi M. Alomari \\ Electrical Engineering Dept. \\ The Australian College of \\ Kuwait, Kuwait \\ m.alomari@ack.edu.kw
}

\author{
Mohammad S. Widyan \\ Electrical Engineering Dept. \\ The Hashemite University \\ Jordan \\ mohammadwidyan@hu.edu.jo
}

\author{
Mohammed Abdul-Niby \\ Electrical Engineering Dept. \\ The Australian College of \\ Kuwait, Kuwait \\ m.nibi@ack.edu.kw
}

\author{
Alireza Gheitasi \\ Electrical Engineering Dept. \\ The Australian College of \\ Kuwait, Kuwait \\ a.gheitasi@ack.edu.kw
}

\begin{abstract}
The use of a unified power flow controller (UPFC) to control the bifurcations of a subsynchronous resonance (SSR) in a multi-machine power system is introduced in this study. UPFC is one of the flexible AC transmission systems (FACTS) where a voltage source converter (VSC) is used based on gate-turn-off (GTO) thyristor valve technology. Furthermore, UPFC can be used as a stabilizer by means of a power system stabilizer (PSS). The considered system is a modified version of the second system of the IEEE second benchmark model of subsynchronous resonance where the UPFC is added to its transmission line. The dynamic effects of the machine components on SSR are considered. Time domain simulations based on the complete nonlinear dynamical mathematical model are used for numerical simulations. The results in case of including UPFC are compared to the case where the transmission line is conventionally compensated (without UPFC) where two Hopf bifurcations are predicted with unstable operating point at wide range of compensation levels. For UPFC systems, it is worth to mention that the operating point of the system never loses stability at all realistic compensation degrees and therefore all power system bifurcations have been eliminated.
\end{abstract}

Keywords-Hopf Bifurcations; Subsynchronous Resonance; UPFC; GTO

\section{INTRODUCTION}

Series compensation is used in power systems as a valuable technique to effectively increase power transfer capability and improve stability. SubSynchronous Resonance (SSR) is considered a major drawback of series compensation and can be defined as the electromechanical interaction between electrical resonant circuits of the transmission system and the torsional natural frequencies of the turbine-generator rotor. Basically, SSR can cause shaft fatigue as well as damage or failure. The subsynchronous torques on the rotor is an issue of great concern because the turbine-generator shaft has natural modes of oscillation that are typical of any spring-damper-mass system. SSR has been considered intensively since 1970, when a shaft failure took place to its turbine-generator unit in the major transmission network with conventional series compensation in southern California. The bifurcation phenomenon also occurs in power systems. Researchers study power system dynamics from the nonlinear dynamics point of view utilizing the modern nonlinear theory (bifurcation theory). Bifurcation is defined as a qualitative change in the features of a system, such as the types and number of solutions when a small variation occurs in the parameters of the system.

Bifurcation theory has been used to show the presence of the dynamic bifurcation (Hopf bifurcation) in a single machine infinite bus (SMIB) power system in the case of neglecting the dynamics of the damper windings and the automatic voltage regulator (AVR) of the synchronous generator [1]. The results show that the system operating point losses stability through supercritical Hopf bifurcation. Bifurcation theory has also been applied on modeling the characteristics of the BOARDMAN generator with respect to the North-Western American power system and the CHOLLA generator with respect to the SOWARA station in the USA. The effect of the linear and nonlinear controllers on the bifurcations of SSR of CHOLLA generator is studied in [2]. It is found that the linear controllers increase the compensation level at which SSR occurs while the nonlinear controller does not affect the location and type of the Hopf bifurcation. It is also shown that the larger the nonlinear controller gain is, the smaller the amplitude of the limit cycle tends to be. Additionally, the bifurcation theory has been applied on the first system of the IEEE second benchmark model of SSR where supercritical Hopf bifurcation is experienced [3]. A nonlinear controller of the $K\left(\omega_{g}^{3}-\omega_{1}^{3}\right)$ form has been designed where all bifurcations of the system are eliminated at all realistic compensation factors despite the successive interactions of the subsynchronous electrical mode with the three torsional mechanical modes of the first system of the IEEE second benchmark model of SSR [4].

The recent improvements of power electronic devices have launched the use of flexible AC transmission system (FACTS) controllers in power systems. In fact, FACTS controllers can control the network condition via a very fast approach which in turn can be used to improve the dynamic and steady-state stability of power systems [5]. Utilizing FACTS controllers in power transmission system have led to many applications of these controllers for improving the stability of the existing power network resources as well as providing some operating flexibilities. Basically, FACTS devices have been defined as 
"alternating current transmission system incorporating power electronic-based and other static controllers to enhance controllability and increase power transfer capability" [6]. The most familiar and common FACTS devices are thyristorcontrolled series capacitor (TCSC), static synchronous compensator (STATCOM), static synchronous series compensator (SSSC), static var compensator (SVC) and unified power flow controller (UPFC) [6 -7]. Technically, each of these devices has specific limitations, characteristics and features. In power systems, UPFC is considered as a powerful technique based on economic and technical considerations for controlling active and reactive power flows in a transmission line as well as the bus voltage. In addition, UPFC can be used as a stabilizer with the help of the power system stabilizer (PSS). Controlling the bifurcations of the first system of the IEEE second benchmark model using TCSC has been investigated [8]. It is found that the operating point of the system never loses stability at any realistic firing angle and therefore all bifurcations of the system are eliminated at all practical values of series compensation. Time domain simulations based on the nonlinear dynamical mathematical model after step reduction in the infinite bus voltage and input power coincide with the results of the bifurcation analysis. The effect of SSSC on the bifurcations of the SSR in power system has also been investigated where the effect of replacing the conventional compensation with SSSC is highlighted [9]. Varying the SSSC controller reference voltage changes the compensation degree. The results show that the operating point of the system never loses stability at any realistic compensation degree in case of SSSC i.e. all bifurcations of the system have been eliminated. In this paper, the effect of incorporating the second system of the IEEE second benchmark model of SSR with UPFC on the Hopf bifurcation of the system is investigated which is considered as the main contribution of the paper where shunt current and series voltage controllers are considered as controllers for UPFC. The paper is constructed in the following manner: Section 2 describes the system under study and its nonlinear dynamical mathematical model including the system controllers. In section 3, the model of the UPFC with three-level VSC is outlined. Numerical simulation results in case of including UPFC as compared with the case of conventional compensation without UPFC are presented in section 4. Finally conclusions are drawn in section 5.

\section{SYSTEM DESCRIPTION AND MATHEMATICAL MODEL}

The system considered in this study is the second system of the IEEE second benchmark model of subsynchronous resonance (Figure 1) [10]. It is a two-machine infinite-bus (TMIB) power system connected to a single seriescompensated transmission line where the terminals of the two generators are connected at the same bus. The capacitive reactance varies in the range of 0 to $100 \%$ of the transmission line inductive reactance. UPFC is incorporated at the end of the transmission line injecting certain amounts of voltage after the capacitive reactance.

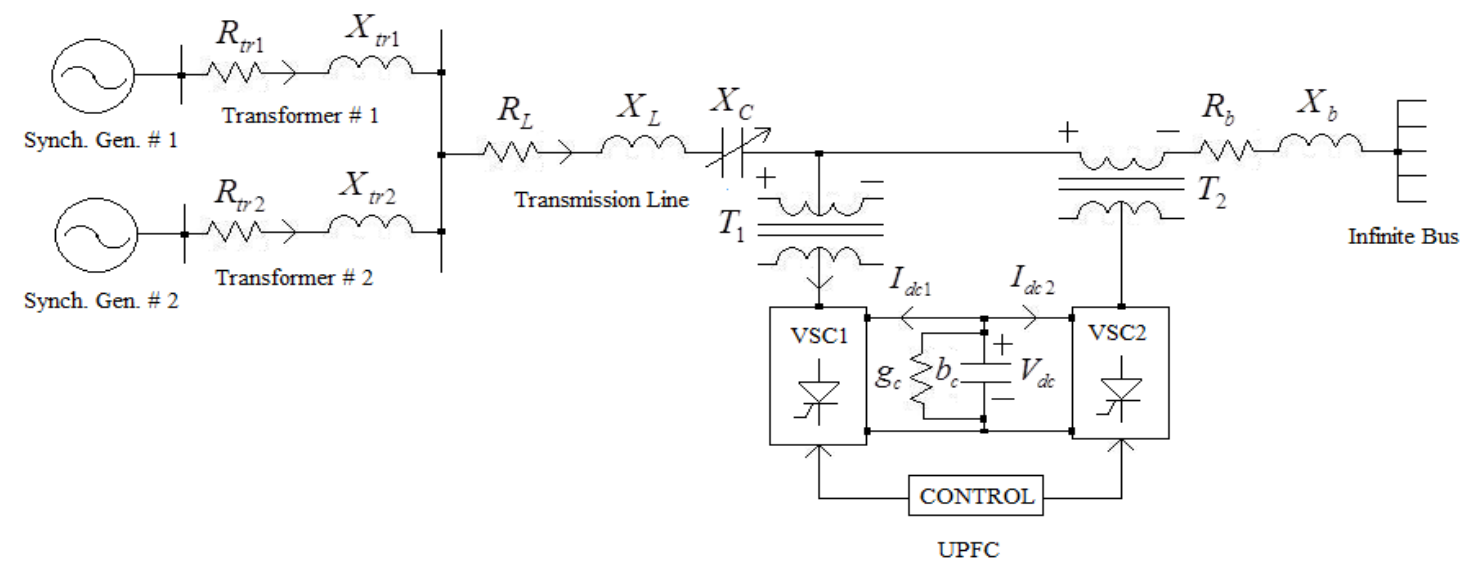

Fig. 1. Electrical system under study (modified version of second system of the IEEE second benchmark model of SSR

The electro-mechanical systems of the two generators and the data of the electrical and mechanical systems are provided in [10]. Each generator is represented in its own rotor frame of reference with the proper transformations as the substitution of the two generators in one equivalent generator will change the resonance characteristics. The electrical system consists of the nonlinear dynamical mathematical model of the two synchronous generators and that of the transmission line in $\mathrm{dq}$ stationary reference frame related to the d-axis stator winding, $\mathrm{q}$-axis stator winding, d-axis rotor field winding, q-axis rotor damper winding and d-axis rotor damper winding utilizing Park's transformation. Each section of the mechanical system of the two generators is represented by second order ordinary differential equation (swing equation) which is presented in state space model as two first order ordinary differential equations. The mathematical model of the electrical and mechanical systems is given in [11]. As a result, this systems can be mathematically represented as a set of first order nonlinear ordinary differential equations with the compensation factor $\left(\mu=X_{c} / X_{L}\right)$ as a bifurcation parameter. Hence, bifurcation theory can be applied to this nonlinear dynamical system which can be written in the following form:

$$
\frac{d x}{d t}=F(x ; \mu)
$$


where $x$ is the vector of state variables $x_{1}, x_{2}, \ldots, x_{n}, n$ is an integer number representing the number of state variables, $F$ is the field vector and $\mu$ is the control parameter of the system which is in this study is the transmission line compensation degree.

Unified power flow controller (UPFC) is a FACTS device utilizing a voltage source converter (VSC). It depends on gateturn-off (GTO) thyristor valve technology and can be designed as a coordinated combination of a static synchronous series compensator (SSSC) and a static synchronous compensator (STATCOM), which uses the same technology, coupled through a common DC voltage link [12-22]. UPFC is a multifunctional FACTS controller where its primary duty is to control the power flow [23]. The secondary functions of the UPFC are voltage control, transient and steady-state stability improvement and oscillation damping. Recently, there is a rising attention in studying UPFC which includes its modeling [24], its effect on controlling the power flow [25] and its capability to improve system transient stability [26]. However, so far, little work has been done to investigate the effect of UPFC on SSR problems. Damping the oscillations of The IEEE first benchmark system of SSR using UPFC has been examined [27]. A compensator utilizing specific technique based on model control theory with two feedback signals is employed to generate two supplementary damping signals.

The two port voltages of UPFC are regulated through control of shunt current and series real voltage as shown in Figure 2. Moreover, it has various operating control modes such as line impedance compensation, voltage and power regulation. The UPFC is realized by two three-level 12-pulse voltage source converters (VSC). It consists of a shunt connected voltage source converter (VSC1) and a series connected voltage source converter (VSC2). VSC2 injects a series voltage while VSC1 is controlled to inject reactive current. The series and shunt branches of UPFC can generate/absorb reactive power independently and the two branches can exchange active power. The injection of series reactive voltage provides active series compensation while the injection of the shunt reactive current can be controlled to regulate the voltage at the bus where VSC1 is connected. The injection of series real voltage (in-phase with the line current) can be controlled to regulate the reactive power in the line or the voltage at the output port of the UPFC. UPFC can be viewed as a two port device on a single phase basis [28].

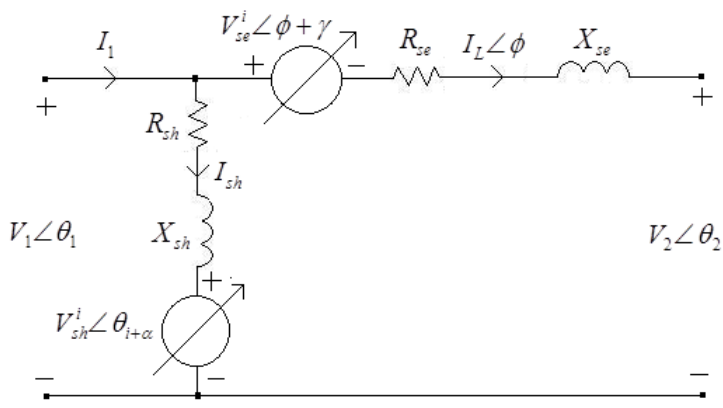

Fig. 2. UPFC as a two port FACTS controller

\section{MATHEMATICAL MODEL OF UPFC AND ITS CONTROLLERS}

\section{A. Mathematical Model of UPFC}

Typically, the converter in the power circuit of a UPFC is either a multi-pulse or a multi-level configuration. In UPFC, it is considered to change the magnitude of AC output voltage of the converter without varying the magnitude of the dc voltage. This can be accomplished by utilizing pulse width modulation (PWM) with two-level topology which demands higher switching frequency and leads to increased losses. The objective can be accomplished by varying dead angle $\beta$ with fundamental switching frequency of the three-level converter topology [29]. The converters that allow the variation of both magnitude and the phase angle of the converter output voltage are classified as type-1 converters [30]. In this study, a combination of multi-pulse and three-level configuration is used [31]. The three-level converter topology is considered to reduce the harmonic distortion on the aside [5, 29, 32-33]. Both the shunt and series branches of the UPFC contain 12-pulse converter with three-level poles. A special design of a converter operation by switching functions to improve a complete three-phase model of UPFC is considered [31].

UPFC can be designed by transforming the three-phase voltages and currents to D-Q variables using Park's transformation. This is can be done when switching functions are approximated by their fundamental frequency components neglecting [34]. As shown in Figure 2, the resistance and reactance of the interfacing transformer of shunt and series VSC are symbolized as $R_{s h}, X_{s h}, R_{s e}$ and $X_{s e}$, respectively. The magnitude control of shunt and series converter output voltages $V_{s h}^{i}$ and $V_{s e}^{i}$ are accomplished by modulating the conduction period affected by dead angles $\beta_{s h}$ and $\beta_{s e}$ of individual converters while DC voltage is maintained constant. The shunt converter output voltage $V_{s h}^{i}$ can be written as:

$$
\begin{aligned}
& V_{s h}^{i}=\sqrt{V_{D(s h)}^{2}+V_{Q(s h)}^{2}} \\
& V_{D(s h)}=k_{m 1} V_{d c} \sin \left(\theta_{1}+\alpha\right) \\
& V_{Q(s h)}=k_{m 1} V_{d c} \cos \left(\theta_{1}+\alpha\right)
\end{aligned}
$$

Where $k_{m 1}=(2 \sqrt{6} \pi) \rho_{s h} \cos \left(\beta_{s h}\right)$ for a 12-pulse converter, $\rho_{s h}$ is the transformation ratio of the interfacing transformer $T_{1}$ and $\alpha$ is the angle by which the fundamental component of shunt converter output voltage leads the port-1 voltage $V_{1}$.

On the other hand, the series converter output voltage $V_{s e}^{i}$ can also be written as:

$$
\begin{aligned}
& V_{s e}^{i}=\sqrt{V_{D(s e)}^{2}+V_{Q(s e)}^{2}} \\
& V_{D(s e)}=k_{m 2} V_{d c} \sin \left(\theta_{1}+\gamma\right) \\
& V_{Q(s e)}=k_{m 2} V_{d c} \cos \left(\theta_{1}+\gamma\right)
\end{aligned}
$$


where $k_{m 2}=(2 \sqrt{6} p) r_{s e} \cos \left(b_{s e}\right), \rho_{s e}$ is the transformation ratio of the interfacing transformer $T_{2}$ and $\gamma$ is the angle by which the fundamental component of series converter output voltage leads the port- 2 current $I_{2}$. The DC side capacitor can be mathematically described as:

$$
\frac{d V_{d c}}{d t}=-\frac{g_{c} \omega_{B}}{b_{c}}-I_{d c 1} \frac{\omega_{B}}{b_{c}}-I_{d c 2} \frac{\omega_{B}}{b_{c}}
$$

where $I_{d c 1}=-\left[k_{m 1} \sin \left(q_{1}+a\right) I_{s h, D}+k_{m 1} \cos \left(q_{1}+a\right) I_{s h, Q}\right], I_{s h, D}$ and $I_{s h, Q}$ are D-Q components of the shunt converter current, respectively and:

$$
I_{d c 2}=-\left[k_{m 2} \sin (\phi+\gamma) I_{2, D}+k_{m 2} \cos (\phi+\gamma) I_{2, Q}\right] .
$$

\section{B. Shunt Current Controller}

The real current drawn by the shunt VSC is controlled by phase angle $\alpha$ and the reactive current by modulating the converter output voltage magnitude which depends on $\beta_{s h}$. The dynamical equations of the shunt current control are presented in details in [28]. The schematic representation of type-1 controller for shunt current control is shown in Figure 3. In order to keep the port-1 voltage magnitude at the specified value, the reactive current reference of shunt converter can be maintained constant or regulated.

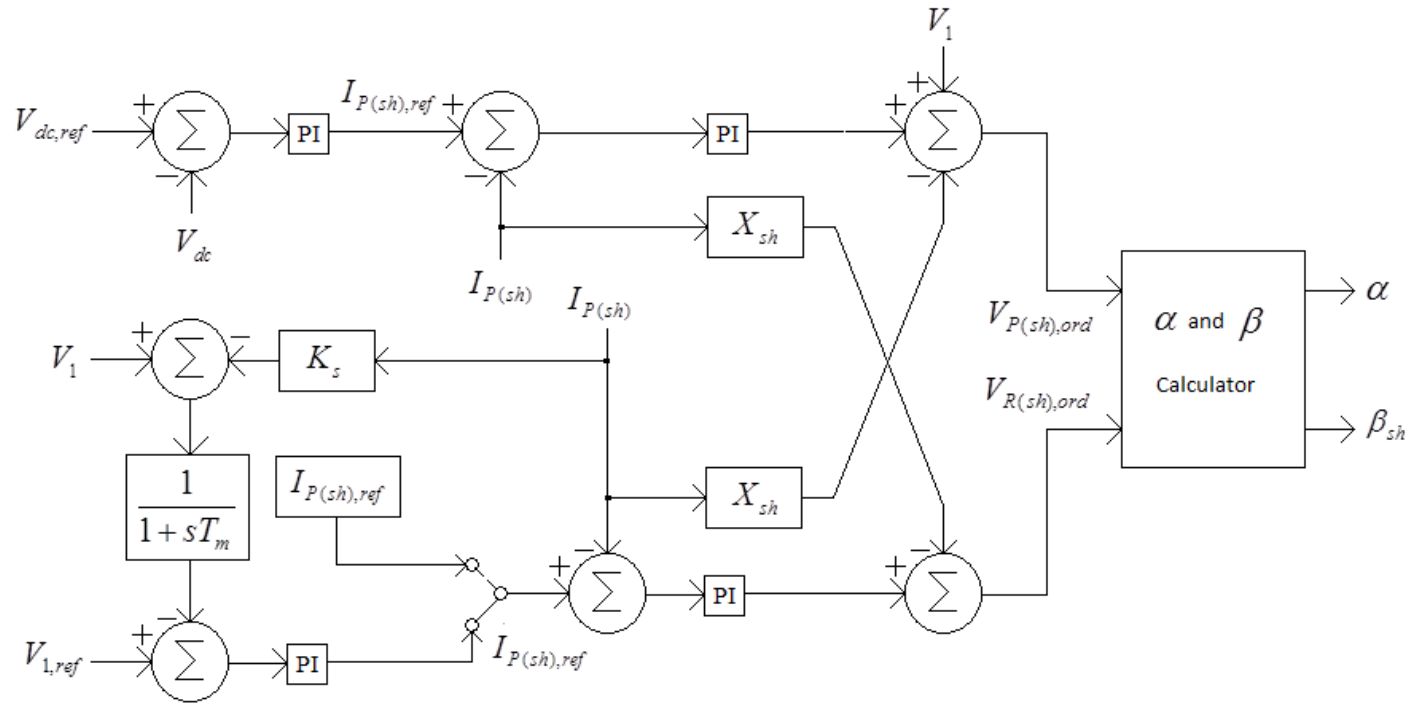

Fig. 3. Type-1 shunt current controller

In Figure 3, real and reactive currents can be represented as:

$$
\begin{aligned}
& I_{P(s h)}=I_{D(s h)} \sin \left(\theta_{1}\right)+I_{Q(s h)} \cos \left(\theta_{1}\right) \\
& I_{R(s h)}=-I_{D(s h)} \cos \left(\theta_{1}\right)+I_{Q(s h)} \sin \left(\theta_{1}\right)
\end{aligned}
$$

Where $\alpha$ and $\beta_{\text {sh }}$ are calculated as:

$$
\begin{gathered}
\alpha=\tan ^{-1}\left[\frac{V_{R(s h), o r d}}{V_{P(s h), o r d}}\right] \\
\beta_{s h}=\cos ^{-1}\left[\frac{\sqrt{V_{P(s h), o r d}^{2}+V_{R(s h), o r d}^{2}}}{k \rho_{s h} V_{d c}}\right]
\end{gathered}
$$

In the case the shunt VSC is drawing real current and inductive reactive current, (9) and (10) should be positive values.

\section{Series Voltage Controller}

Figure 4 shows the type- 1 controller structure for series converter. The independent injection of real and reactive voltage causes two operating combinations of series converter. The first one is about constant reactive voltage and port-2 voltage control while the second is about constant reactive voltage and constant resistance emulation.

The active power can be regulated and/or modulated by controlling series reactive voltage reference [35-37]. On the other hand, the reactive power in the line can be regulated by controlling series real voltage injection and this is equivalent to port-2 voltage control [28]. The voltage at port-2 of the UPFC is related to that at port-1 and the voltage injected by series VSC. For simplicity, the series transformer reactance is clubbed with the line impedance. The voltage relation is given by:

$$
\begin{aligned}
V_{2} & =\sqrt{V_{D 2}^{2}+V_{Q 2}^{2}}=\sqrt{\left(V_{D 1}-V_{D(s e)}\right)^{2}+\left(V_{D 1}-V_{D(s e)}\right)^{2}} \\
& =\sqrt{\left(V_{P 1}-V_{P(s e)}\right)^{2}+\left(V_{R 1}-V_{R(s e)}\right)^{2}}
\end{aligned}
$$


where $V_{P 1}$ and $V_{R 1}$ are the in-phase and quadrature components of port-1 voltage $V_{l}$ with respect to port-2 current and $V_{P(s e)}$ and $V_{R(s e)}$ are the in-phase and quadrature components of $V_{s e}^{i}$ with respect to port- 2 current and can be written as:

$$
\begin{aligned}
& V_{P(s e)}=V_{D(s e)} \sin \phi+V_{Q(s e)} \cos \phi \\
& V_{R(s e)}=V_{D(s e)} \cos \phi+V_{Q(s e)} \sin \phi
\end{aligned}
$$

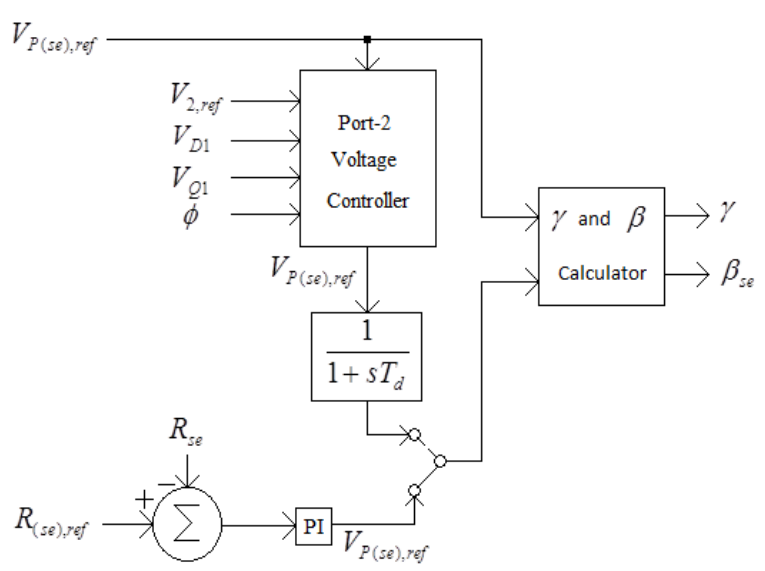

Fig. 4. Type-1 Series voltage controller

$V_{P 1}$ and $V_{R 1}$ can be computed from $V_{D 1}, V_{Q 1}$ and $\phi$ by assuming $V_{R(s e)}=V_{R(s e), \text { ref. }}$. Real voltage $V_{P(s e)}$ can be calculated to be injected to obtain desired magnitude of $V_{2}$ as shown in Figure 4 . In this case, there are two solutions of $V_{P(s e)}$. The solution which has the lower magnitude is chosen. In Figure 4, $\gamma$ and $\beta_{\text {se }}$ are expressed as:

$$
\begin{gathered}
\gamma=\tan ^{-1}\left[\frac{V_{R(s e), \text { ord }}}{V_{P(s e), \text { ord }}}\right] \\
\beta_{s e}=\cos ^{-1}\left[\frac{\sqrt{V_{P(s e), r e f}^{2}+V_{R(s e), r e f}^{2}}}{k \rho_{s e} V_{d c}}\right]
\end{gathered}
$$

\section{NUMERICAL SIMULATIONS}

\section{A. System Response without UPFC}

This subsection presents the results of the numerical simulations when the power system has no UPFC. In this case, the mathematical model of the system is represented by 27 ordinary nonlinear coupled differential equations [11]. The synchronous generators are heavily loaded with an output active power of 0.9 pu and output reactive power of $0.43 \mathrm{pu}$. The response of the system with $1 \%$ initial disturbance on the speed of the generator at $\mu=0.25$ without UPFC is shown in Figure 5. It can be concluded that the operating point of the system is unstable. Figure 6 shows the bifurcation diagram of the power system in this case, which is the steady-state value of the first generator delta angle as function of the compensation degree. Two Hopf bifurcation points are predicted. The power system has a stable operating point to the left of $H_{1} \gg 0.1984$ and to the right of $H_{2} \gg 0.8241$ and an unstable operating point between $H_{1}$ and $H_{2}$.
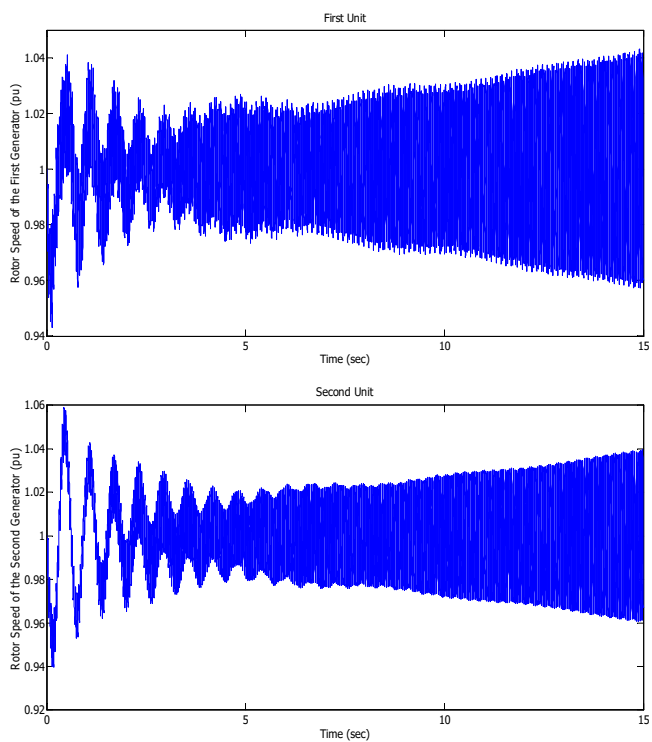

Fig. 5. Rotor speed of the generators at $\mu=0.25$ with $1 \%$ initial disturbance in rotor speed of the generators (without UPFC).

The operating point loses stability through subcritical Hopf bifurcation at $H_{1}$. It returns to stability case in a reverse Hopf bifurcation at $\mathrm{H}_{2}$. In Hopf bifurcation, a pair of complex conjugate eigenvalues of the linearized model around the operating point transversally cross from left to right side of the complex plane or vice versa. The type of the first Hopf bifurcation at $H_{l}$ which decides whether the limit cycles created due to the Hopf bifurcation are stable or unstable has been determined numerically by observing the time response of the system after small disturbance slightly before $H_{l}$.

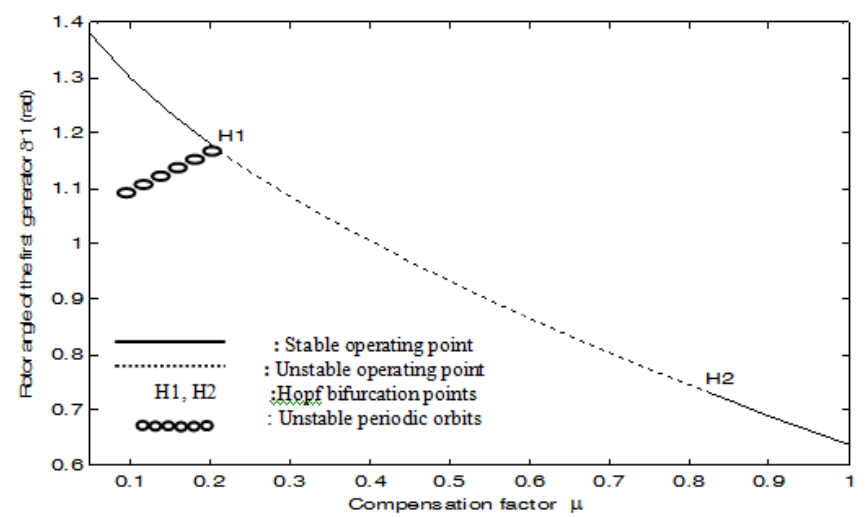

Fig. 6. Bifurcation diagram showing variation of the first generator rotor angle with the compensation factor (without UPFC).

Figure 7 shows the response of the system with $2 \%$ initial disturbance on the speed of the first generator at $\mu=0.1975$, 
which is slightly lower than $H_{1}$. It can be concluded that the system operating point has an unstable behavior. Consequently, the type of this Hopf bifurcation is subcritical and the periodic solution emerging at the bifurcation point is unstable.
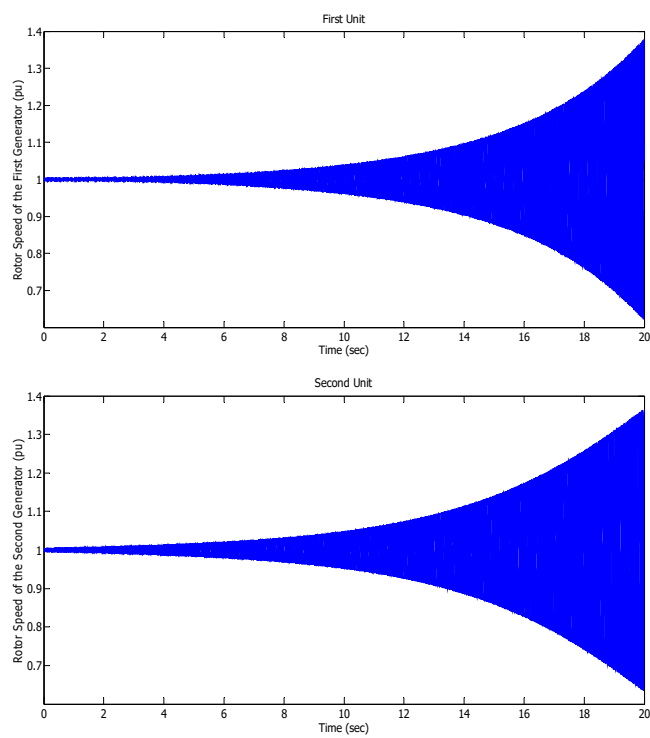

Fig. 7. Rotor speed of the generators at $\mu=0.1975$ (slightly lower than $\mathrm{H}_{1}$ ) with $2 \%$ initial disturbance in rotor speed of generator (without UPFC).

\section{B. System Response with UPFC}

The system response in case of adding UPFC after $2 \%$ initial disturbance in generator rotor speed at $\mu=0.6$ is shown in Figure 8. In fact, testing of the system at all values of $\mu$ shows that the system operating point does not lose stability for all realistic values of compensation factor. Hence, the system never experiences any bifurcations for this case. As a result, it can be concluded that UPFC has succussed in stabilizing the system operating point at all realistic bifurcation parameters and therefore the Hopf bifurcation will never occur for all values of the compensation factor.

\section{CONCLUSIONS}

In this study, a controller is designed and considered for UPFC to control bifurcations of subsynchronous resonance in multi-machine power system. The system considered is a modified version of the second system of the IEEE second benchmark model of subsynchronous resonance where the compensation degree $\mu=X_{c} / X_{L}$ is the bifurcation parameter. UPFC is used as a powerful technique based on economic and technical considerations for controlling active and reactive power flows in ac transmission lines as well as controlling the bus voltage. It can also be used to improve the power system stability with the help of the Power System Stabilizer (PSS). When UPFC is not included, it is found that as the compensation factor increases the system operating point loses stability through subcritical Hopf bifurcation point at relatively early compensation degree before regaining the stability at a very late compensation level in a reverse Hopf bifurcation. When UPFC is added to the system, the analysis does not predict any bifurcations at all realistic compensation degrees and therefore one can conclude that the UPFC and its controllers have succussed in eliminating all bifurcations of the power system at all practical compensation degrees.
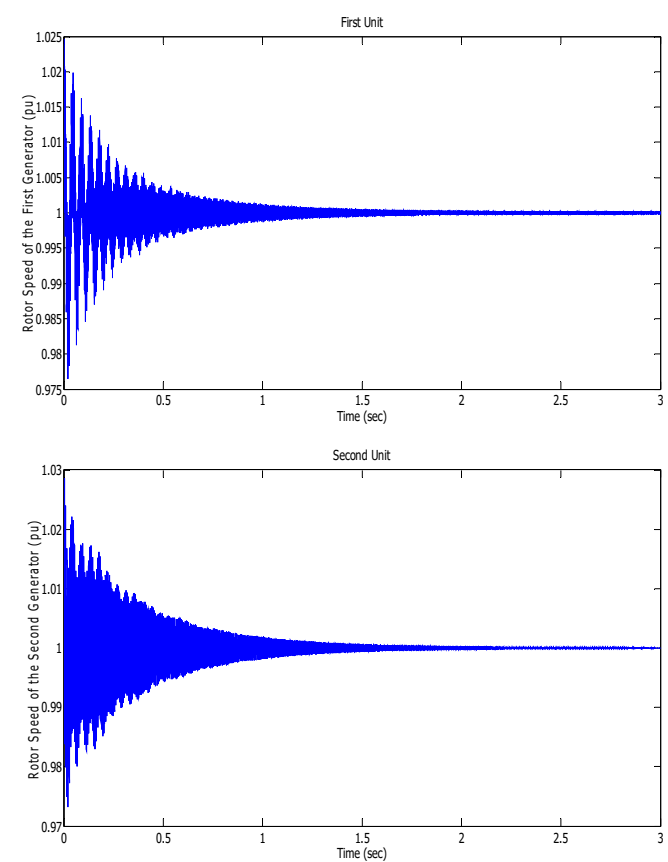

Fig. 8. Rotor speed of the first and second generator at $\mu=0.60$ with $2 \%$ initial disturbance in rotor speed of generator (with UPFC controller).

\section{REFERENCES}

[1] W. Zhu, R. R. Mohler, R. Spce, W. A. Mittelstadt, D. Maratukulman, "Hopf Bifurcation in a SMIB Power System with SSR", IEEE Trans. on Power Systems, Vol. 11, No. 3, pp. 1579-1584, 1996

[2] A. M. Harb, Application of bifurcation theory to subsynchronous resonance in power systems, Doctoral Dissertation, Virginia Polytechnic Institute and State University, USA, 1996

[3] A. M. Harb, M. S. Widyan, "Modern nonlinear theory as applied to SSR of the IEEE second benchmark model", IEEE Bologna Power Tech. 2003 Conf., Bologna, Italy, June 23-26, 2003

[4] A. M. Harb, M. S. Widyan, "Chaos and bifurcation control of SSR in the IEEE second benchmark model", Chaos, Solitons and Fractals Journal, Vol. 21, pp. 537-552, 2004

[5] N.G. Hingorani, L. Gyugyi, Understanding FACTS, IEEE Press, New York, 2000.

[6] Cigre/IEEE FACTS Working Group, FACTS Overview, IEEE Power Engineering Society, No. 95 TP108, 1995

[7] C. A. Canizares, "Power Flow and Transient Stability Models of FACTS Controllers for Voltage and Angle Stability Studies", Proceedings of the 2000 IEEE/PES Winter Meeting, Singapore, January, 2000

[8] M. S. Widyan, "Controlling Chaos and Bifurcations of SSR Using TCSC", International Journal of Modelling and Simulation, Vol. 30, No. 3, pp. 308-314, 2010

[9] M. S. Widyan, "Controlling chaos and bifurcations of SMIB power system experiencing SSR phenomenon using SSSC", International Journal of Electrical Power and Energy Systems, Vol. 49, pp. 66-75, 2013

[10] IEEE SSR Working Group, "Second Benchmark Model for Computer Simulation of Subsynchronous Resonance", IEEE Trans. on Power Apparatus and Systems. Vol. PAS- 104, No. 5, 1057-1064, 1985 
[11] M. M. Alomari, B. S. Rodanski, "The Effects of Machine Components on Bifurcation and Chaos as Applied to Multi-machine System", in: Topics on Chaotic Systems- Selected Papers from CHAOS 2008 International Conference, World Scientific Publishing Co. Pte. Ltd, 2009.

[12] M. L. Kothari, N. Tambey, "Design of UPFC Controllers for a Multimachine System", IEEE PES Power Systems Conference and Exposition, USA, October 10-13, 2004

[13] A. Ali, A. Mehdi, "A multi-objective gravitational search algorithm based approach of power system stability enhancement with UPFC", Journal of Central South University, Vol. 20, No. 6, pp. 1536-1544, 2013

[14] A. Kumar, C. Sekhar, "Congestion management with FACTS devices in deregulated electricity markets ensuring laudability limit", International Journal of Electrical Power \& Energy Systems, Vol. 46, pp. 258-73, 2013

[15] A. N. Hussain, F. Malek, M. A. Rashid, L. Mohamed, I. Daut, "UPFC device application on power system oscillations to improve the damping performance", 4th International Conference on Manufacturing Science and Engineering, pp. 830-837, China, March 30-31, 2013

[16] A. N. Hussain, F. Malek, M. A. Rashid, L. Mohamed, N. A. Mohd Affendi, "Optimal coordinated design of multiple damping controllers based on PSS and UPFC device to improve dynamic stability in the power system", Mathematical Problems in Engineering, Vol. 2013, pp. $1-15,2013$

[17] A. Safari, "PSO algorithm for UPFC based output feedback damping controller", International Journal of Control and Automation, Vol. 6, No. 1, pp. 33-46, 2013

[18] A. Sode-Yome, N. Mithulananthan, K. Y. Lee, "Comprehensive comparison of FACTS devices for exclusive loadability enhancement", IEEJ Transactions on Electrical and Electronic Engineering, Vol. 8, No.1, pp. 7-18, 2013

[19] B. Gopinath, S. S. Kumar, J. Michael, "Stability improvement in power systems using unified power flow controller (UPFC)", International Conference on Energy Efficient Technologies for Sustainability, pp. $392-397,2013$

[20] E. Gholipour, G. Isazadeh, "Design of a new adaptive optimal wide area IPFC damping controller in Iran transmission network," International Journal of Electrical Power and Energy Systems, Vol. 53, No. 1, pp. 529-539, 2013

[21] I. M. Wartana, J. G. Singh, W. Ongsakul, S. Sreedharan, "Optimal placement of FACTS controllers for maximising system loadability by PSO", International Journal of Power and Energy Conversion, Vol. 4, No. 1, pp. 9-33, 2013

[22] J. Khazaie, M. Mokhtari, S. Badkubi, M. Khalilian, D. Nazarpour, "Subsynchronous resonance mitigation via distributed power flow controller", International Transactions on Electrical Energy Systems, Vol. 23, No. 6, pp. 751-766, 2013

[23] L. Gyugyo, T. R. Rietman, A. Edris, C. D. Schalider, D. R. Torgerson, S L. Williams, "The Unified Power Flow Controller: a New Approach to Power Transmission Control", IEEE Transactions on Power Delivery, Vol. 10, No. 2, pp. 1085-1097, 1995

[24] A. Nabavi-Niaki, M. R. Iravam, "Steady-State and Dynamic Models of Unified Power Flow Controller (UPFC) for Power System Studies", IEEE Transactions on Power Systems, Vol. 11, No. 4, pp. 1937-1943, 1996

[25] K. S. Smith, L. Ran, J. Penman, "Dynamic Modeling of a Unified Power Flow Controller", IEE Proceedings-Generation, Transmission and Distribution, Vol. 144, pp. 7-12, 1997

[26] S. Limyingcharoen, U. D. Annakage, N. C. Pahalawaththa, "Effects of Unified Power Flow Controllers on Transient Stability", IEE Proceedings-Generation, Transmission and Distribution, Vol. 145, pp. 182-188, 1998

[27] W. Bo, Z. Yan, "Damping Subsynchronous Oscillation Using UPFC - A FACTS Device", Proc. Int. Conf. Power System Technology, Vol. 4, China, October 13-17, 2002
[28] K. R. Padiyar, A. M. Kulkarni, "Control Design and Simulation of Unified Power Flow Controller", IEEE Trans. Power Deliv. Vol. 13, No. 4, pp. 1348-1354, 1998.

[29] K. Sen Kalyan, J. Stacy Eric, , "UPFC - Unified Power Flow Controller: Theory, Modelling and Applications", IEEE Trans. Power Delivery, Vol. 13, No. 4, pp. 1453-1460, 1998

[30] M. Schauder, "Vector Analysis and Control of Advanced Static VAR Compensators", IEE Proceedings-Generation, Transmission and Distribution, Vol. 140, No. 4, pp. 299-306, 1993

[31] K. R. Padiyar, N. Prabhu, "Analysis of Subsynchronous Resonance with Three-Level 12-Pulse VSC Based SSSC", IEEE Power System Stability and Control-TENCON 2003 Conference, pp. 76-80, October 14-17, 2003

[32] R. W. Menzis, Y. Zhuang, "Advanced Static Compensation Using A Multilevel GTO Thyristor Inverter”, IEEE Trans. Power Deliv., Vol. 10, No. 2, pp. 732-738, 1995

[33] J. B. Ekanayake, N. Jenkins, "Mathematical Models of a Three-Level Advanced Static Var Compensator", IEE Proc. Generat. Transm. Distrib. Vol. 144, No. 2, pp. 201-206, 1997

[34] K. R. Padiyar, Power System Dynamics - Stability and Control, second ed., B.S. Publications, Hyderabad, 2002

[35] C. D. Schauder, L. Gyugyi, M. R. Lund, D. M. Hamai, T. R. Rietman, D. R. Torgerson, A. Edris, "Operation of the Unified Power Flow Controller (UPFC) Under Practical Constraints", IEEE Trans. Power Deliv., Vol. 13, No. 2, pp. 630-639, 1998

[36] B. A. Renz, A. S. Mehraben, C. Schauder, E. Stacey, L. Kovalsky, L. Gyugyi, A. Edris, "AEP Unified Power Flow Controller Performance", IEEE Trans. Power Delivery, Vol. 14, No. 4, pp. 1374-1381, 1999

[37] K. Esakki Shenbaga Loga, S. Umayal, T. C. Asha Raghavan, "Mitigation of Subsynchronous Resonance in Series Compensated Wind Farm Using UPFC and ANN with Back Propagation Algorithm", International Journal of Engineering Research and General Science, Vol. 3, No. 2, 2015.

\section{AUTHORS PROFILE}

Majdi M. Alomari (BSc 2001, MSc 2004, PhD 2011) is an Assistant Professor in Electrical Engineering Department at the Australian College of Kuwait. His research interests include: Power System Analysis, Power System Stability and Control, Power System Planning, Power System Protection, Power Electronics, Electrical Machines and Drives, Electric Machine Design, Renewable Energy, Smart Grid, Energy Planning and Policy, Control Systems, Optimal Control, Nonlinear Dynamics, Linear System Analysis and other related topics.

Mohammad S. Widyan (BSc 2000, MSc 2002, PhD 2006) is an Associate Professor in Electrical Engineering Department at the Hashemite University. His research interests include: Conventional and Permanent-Magnet Electrical Machines Design, Finite Element Technique, Bifurcation Theory, Nonlinear Dynamics and Control, Subsynchronous Resonance in Power Systems (Analysis \& Control), Power System and Electrical Machine Dynamics, Renewable and Hybrid Energy Systems (Wind and Photovoltaic), Dynamical Analysis of Various PV-Powered and Hybrid Electrical Systems, Simulations of Power Electronic Systems in MATLAB.

Mohammed Abdul-Niby received the B.Sc. degree in electrical engineering and MSc in Electronics and communications from the college of engineering, University of Basrah, Basrah, Iraq and the Ph.D degree from the University of Surrey, United Kingdom in 1998. He is currently an Assistant Professor at the Electrical Engineering Department, Australian College of Kuwait, Kuwait. He has published in areas of signal processing and electronic circuits. His current research interest include simulation modeling of semiconductor devices, characterization of implanted silicon, and renewable energies.

Alireza Gheitasi (BSc 2002, MEngSc 2007, Ph.D 2012) has been involved in a number of industrial and research projects since 2008 in New Zealand. He is currently working for the Australian College of Kuwait as a lecturer. His main research interests are power system protection, fault detection and diagnosis and smart grids. 